\title{
Chronic Respiratory Abnormalities in the Multi-Morbid Frail Elderly
}

\author{
Bianca Beghé, MD¹, Enrico Clini, MD' and Leonardo M. Fabbri, MD²,3
}

${ }^{1}$ Department of Medical and Surgical Sciences, Section of Respiratory Diseases, University of Modena and Reggio Emilia, Modena, Italy;

${ }^{2}$ Sahlgrenska University Hospital, Gothenburg, Sweden; ${ }^{3}$ Department of Medical Sciences, University of Ferrara, Ferrara, Italy

\section{ABSTRACT}

Two-thirds of people aged $\geq 65$ years have multi-morbidity. Multi-morbidity includes both physical and mental health conditions, as anxiety and depression, that almost invariably affect patients with multiple symptomatic chronic diseases.

Management of a patient with any of the chronic diseases that are part of multi-morbidity is not just the management of that single index disease, but must include the active search and proper treatment of concomitant chronic diseases. The presence of concomitant chronic diseases should not alter the management of the index disease (e.g., chronic obstructive pulmonary disease [COPD]), and concomitant chronic diseases should be treated according to single diseases guidelines regardless of the presence of the index disease, obviously with careful consideration that this choice implies complex management, polypharmacy and potential adverse effects. Preliminary management programs suggest that a holistic integrated approach might improve quality of life and reduce hospital admissions and death in these multimorbid patients. (BRN Rev. 2017;3:247-66)

Corresponding author: Leonardo M. Fabbri, leonardo.fabbri20@gmail.com

Key words: Chronic bronchitis. Cigarette smoking. Emphysema. Frailty. Inactivity. 


\section{INTRODUCTION}

The improvement in socio-sanitary conditions and of medicine and technology has increased dramatically the lifespan of the population, with a global median life expectancy at birth for both sexes of 71.4 years and a median healthy life expectancy (HALE) of 63.1 years $^{1}$, suggesting that longer survival does not translate into longer healthy life but rather in several life years associated with frailty, disability, and multi-morbidity ${ }^{2-4}$.

The burden of noncommunicable diseases and issues in prevention, detection, and treatment have been recently reviewed in the most prestigious medical journals ${ }^{2,3}$ and also in a specific topic on the guideline from The National Institute for Health and Care Excellence (NICE) organization ${ }^{5,6}$.

Multi-morbidity is related to frailty and disability and, in fact, these terms are often used interchangeably, whereas they represent three distinct clinical concepts, albeit not yet clearly defined ${ }^{5-7}$.

\section{FRAILTY}

Frailty is defined as a condition characterized by reduced biological reserves which puts an individual at risk when facing minor stressors. A minor stress puts a frail person at risk of falls and fluctuating disability which may increase care needs, hospital and care home admissions. Identifying someone as frail may be a useful way of identifying those people with multi-morbidity who would particularly benefit from optimizing medicines and treatments.

\section{DISABILITY}

Disability is defined as difficulty or dependency in the execution of daily activities that are essential for independent living. As disability is considered a dynamic process, older people can recover to a less disabled or nondisabled state ${ }^{8,9}$.

\section{MULTI-MORBIDITY}

Multi-morbidity is defined by the presence of two or more long-term chronic diseases in the same individual ${ }^{5,6,10}$. However, this definition was considered by the NICE commission too broad to be useful, as a very large number of people would have multi-morbidity defined as two or more long term conditions (e.g., 16$58 \%$ of adults in the United Kingdom [UK]), but for many such people their multi-morbidity will present them few problems in their life (e.g., someone with well-controlled asthma and modest hyperdislipidaemia) or in theirhealthcare (e.g., type 2 diabetes, hypertension and hay fever). Thus the NICE guidelines were targeted towards patients with multiple conditions that cause significant problems to everyday functioning or complex management of their care ${ }^{5,6}$. They preferred the term condition as it includes symptom complexes and/or management of major risk factors that are not necessarily classified as disease. In general, an approach to care that takes account of so defined multi-morbidity would better identify people for whom a multi-morbidity approach to care may be appropriate $^{5}$. This would include patients with physical and mental health problems who express difficulties in managing their conditions and treatments, patients who already 


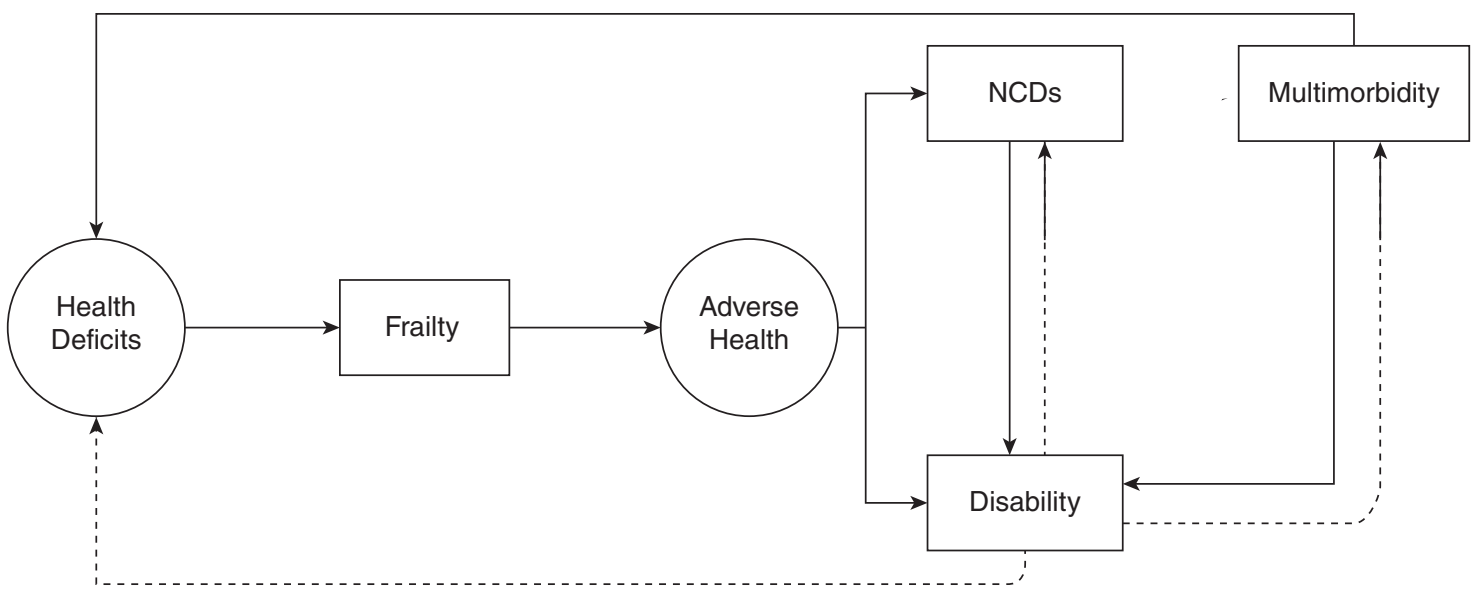

Figure 1. Flowchart of the system failure process. Circles represent inputs/outputs, rectangles represent clinical conditions, continuous lines represent direct effects, dotted lines represent indirect or secondary effects (reproduced with permission from $P$. VillacampaFernandez et al. ${ }^{4}$ )

NCDs: non-communicable diseases.

require input from multiple services, particularly if the addition of further services is being considered. Other potential indicators of these patients suggesting an increased burden are prescription of multiple regular medicines, frequent use of health care resources, or frailty and disability as previously described.

According to one of the largest studies conducted in about one third of the Scotland population (1,751,841 medical records), $42 \%$ of the population had at least one of the 40 conditions counted, and $23 \%$ had multi-morbidity, i.e., $\geq 2$ conditions. Two-thirds of people aged $\geq 65$ years had multi-morbidity, and $47 \%$ had $\geq 3$ conditions. People living in the most deprived areas developed multimorbidity 10-15 years before their more affluent peers. In addition to a poorer quality of life, multi-morbidity is associated with higher mortality, polypharmacy and high treatment burden, higher rates of adverse drug events, and much greater health services use including emergency hospital admissions. Multimorbidity includes both physical and mental health conditions, as anxiety and depression, that almost invariably affect patients with multiple symptomatic chronic diseases ${ }^{11}$.

The relationship between frailty, disability and multi-morbidity can be summarized as in the attached flow-chart adapted from Villacampa-Fernández et al. ${ }^{4}$ (Fig. 1).

The most important diseases that contribute to multi-morbidity are reported in table 1 , whereas the number of concomitant chronic diseases and their relationship with age are reported in figures $2 \mathrm{~A}$ and $\mathrm{B}$. 
The weight in term of prevalence and trend in mortality and disability adjusted life-year are reported in figures $2 \mathrm{~A}$ and $\mathrm{B}$ (Table 1 , Fig. 3A and B), from Barnett et $\mathrm{al}^{11}$.

NICE guidelines have been developed for the management of many individual diseases and conditions. The aim of this guideline is to inform patient and clinical decision-making and models of care for people with multi-morbidity who would benefit from an individual approach because of high impact on their quality of life or functioning due to their conditions or their treatments. Although this is a particular concern of generalists such as general practitioners or geriatricians, the guideline is also relevant to specialists since many of the patients they care for will have other significant conditions.

\section{PULMONARY ABNORMALITIES IN MULTIMORBID PATIENTS}

While the field of multi-morbidity has exploded in the last 15 years in term of epidemiologic studies and number of papers, the number of original studies on diagnosis, assessment of severity and more importantly management of multimorbid patients is almost non-existing, almost all studies being related to comorbidities of single index disease.

Thus, in this narrative review, after a general introduction on dyspnoea and exacerbations, we will summarize the results of studies related to single index non-pulmonary disease, with focus on COPD as the most frequent concomitant chronic diseases that has been examined most extensively in other chronic diseases $^{12}$.

\section{DYSPNOEA}

Dyspnoea is not only the cardinal symptom of $\mathrm{COPD}^{13,14}$ and of chronic heart failure ${ }^{15}$, but also a frequent symptom of several other chronic diseases that have been examined as part of multi-morbidity ${ }^{11}$, e.g., ischaemic heart diseases (IHC), atrial fibrillation, anaemia, chronic kidney diseases, chronic liver diseases, obesity, malnutrition and cachexia, hypothyroidism, asthma, interstitial lung diseases, depression just to mention some $\mathrm{e}^{13,16}$. Also, some of the medications used to treat chronic diseases may cause or worsen dyspnoea, e.g., beta-blockers (BB), angiotensin-converting enzyme (ACE) inhibitors, antidepressants.

Thus, dyspnoea is a frequent symptom of frailty, disability and multi-morbidity, particularly in the elderly, but is of course a very nonspecific symptom as it may be caused by a variety of different chronic diseases ${ }^{13,16}$.

The main cardiorespiratory and non-cardiorespiratory conditions associated with dyspnoea in the elderly have been recently reviewed and are summarized below ${ }^{17}$. They include:

- Respiratory Diseases

- Cardiovascular Diseases

- Musculoskeletal abnormalities

- Neuropsychological abnormalities

- Anaemia

- Reduced renal function

- Obesity or cachexia

- Medications

In respiratory diseases, respiratory impairments decrease ventilatory capacity and may lead to dyspnoea at low exertional workloads. 
TABLE 1. List of the 40 disease conditions included in multi-morbidity count (reproduced with permission from Barnett $K^{11}$ )

\begin{tabular}{|c|c|c|c|}
\hline Condition & Variable definition & $\begin{array}{l}\text { Mental/physical } \\
\text { health condition }\end{array}$ & $\begin{array}{l}\text { Prevalence } \\
(\%)\end{array}$ \\
\hline Hypertension & Read code ever recorded & Physical & 13.4 \\
\hline Depression & $\begin{array}{l}\text { Read code recorded in last } 12 \text { months } 0 \mathrm{R} \geq 4 \text { anti-depressant } \\
\text { prescriptions (excluding low dose tricyclics) in last } 12 \text { months }\end{array}$ & Mental & 8.2 \\
\hline Painful condition & $\begin{array}{l}\geq 4 \text { prescription only medicine analgesic prescriptions in last } 12 \text { months } \\
O R \geq 4 \text { specified anti-epileptics in the absence of an epilepsy Read } \\
\text { code in last } 12 \text { months }\end{array}$ & Physical & 7.2 \\
\hline Asthma (currently treated) & Read code ever recorded AND any prescription in last 12 months & Physical & 6.0 \\
\hline Coronary heart disease & Read code ever recorded & Physical & 4.7 \\
\hline Treated dyspepsia & $\begin{array}{l}\geq 4 \text { prescriptions in last } 12 \text { months BNF } 0103 \% \text { excluding antacids } \\
\text { AND NOT ( } \geq 4 \text { NSAIDS OR } \geq 4 \text { aspirin/clopidogrel) }\end{array}$ & Physical & 4.5 \\
\hline Diabetes & Read code ever recorded & Physical & 4.3 \\
\hline Thyroid disorders & Read code ever recorded & Physical & 4.1 \\
\hline $\begin{array}{l}\text { Rheumatoid arthritis, other inflammatory } \\
\text { polyarthropathies \& systematic } \\
\text { connective tissue disorders }\end{array}$ & Read code ever recorded & Physical & 3.4 \\
\hline Hearing loss & Read code ever recorded & Physical & 3.4 \\
\hline Chronic obstructive pulmonary disease & Read code ever recorded & Physical & 3.2 \\
\hline $\begin{array}{l}\text { Anxiety \& other neurotic, stress } \\
\text { related \& somatoform disorders }\end{array}$ & $\begin{array}{l}\text { Read code in last } 12 \text { months } O R \geq 4 \text { anxiolytic/hypnotic prescriptions } \\
\text { in last } 12 \text { months } O R \geq 410 / 25 \text { mg amitriptyline in last } 12 \text { months \& do not } \\
\text { meet the criteria for "Pain" }\end{array}$ & Mental & 3.2 \\
\hline Irritable bowel syndrome & $\begin{array}{l}\text { Read code ever recorded } O R \geq 4 \text { prescription only medicine } \\
\text { antispasmodic prescription in last } 12 \text { months }\end{array}$ & Physical & 3.0 \\
\hline New diagnosis of cancer in last five years & Read code first recorded in last 5 years & Physical & 2.5 \\
\hline Alcohol problems & Read code ever recorded & Mental & 2.4 \\
\hline Other psychoactive substance misuse & Read code ever recorded & Mental & 2.4 \\
\hline Treated constipation & $\geq 4$ laxative prescriptions in last year & Physical & 2.2 \\
\hline Stroke \& transient ischaemic attack & Read code ever recorded & Physical & 2.1 \\
\hline Chronic kidney disease & Read code ever recorded & Physical & 1.9 \\
\hline Diverticular disease of intestine & Read code ever recorded & Physical & 1.9 \\
\hline Atrial fibrillation & Read code ever recorded & Physical & 1.4 \\
\hline Peripheral vascular disease & Read code ever recorded & Physical & 1.3 \\
\hline Heart failure & Read code ever recorded & Physical & 1.1 \\
\hline Prostate disorders & Read code ever recorded & Physical & 0.9 \\
\hline Glaucoma & Read code ever recorded & Physical & 0.9 \\
\hline Epilepsy (currently treated) & Read code ever recorded AND antiepileptic prescription in last 12 months & Physical & 0.8 \\
\hline Dementia & Read code ever recorded & Mental & 0.7 \\
\hline $\begin{array}{l}\text { Schizophrenia (and related non-organic } \\
\text { psychosis) or bipolar disorder }\end{array}$ & $\begin{array}{l}\text { Read code ever recorded/recorded in last } 12 \text { months (code dependent) } \\
\text { OR Lithium prescribed in last } 168 \text { days }\end{array}$ & Mental & 0.7 \\
\hline Psoriasis or eczema & $\begin{array}{l}\text { Read code ever recorded AND } \geq 4 \text { related prescriptions in last } 12 \text { months } \\
\text { (excluding simple emollients) }\end{array}$ & Physical & 0.7 \\
\hline Inflammatory bowel disease & Read code ever recorded & Physical & 0.6 \\
\hline Migraine & $\geq 4$ prescription only medicine anti-migraine prescriptions in last year & Physical & 0.6 \\
\hline
\end{tabular}


TABLE 1. List of the 40 disease conditions included in multi-morbidity count (reproduced with permission from Barnett $K^{11}$ ) (continuation)

\begin{tabular}{|c|c|c|c|}
\hline Condition & Variable definition & $\begin{array}{l}\text { Mental/physical } \\
\text { health condition }\end{array}$ & $\begin{array}{c}\text { Prevalence } \\
(\%)\end{array}$ \\
\hline Blindness \& low vision & Read code ever recorded & Physical & 0.5 \\
\hline Chronic sinusitis & Read code ever recorded & Physical & 0.5 \\
\hline Learning disability & Read code ever recorded & Mental & 0.3 \\
\hline Anorexia or bulimia & Read code ever recorded & Mental & 0.3 \\
\hline Bronchiectasis & Read code ever recorded & Physical & 0.2 \\
\hline Parkinson's disease & Read code ever recorded & Physical & 0.2 \\
\hline Multiple sclerosis & Read code ever recorded & Physical & 0.2 \\
\hline Viral hepatitis & Read code ever recorded & Physical & 0.1 \\
\hline Chronic liver disease & Read code ever recorded & Physical & 0.1 \\
\hline
\end{tabular}

In addition, dead space ventilation may be greater in individuals with respiratory conditions (e.g., COPD), further exacerbating dyspnoea through greater ventilatory demand.

Cardiovascular impairments decrease the delivery and distribution of oxygen to the exercising muscle, which reduces its aerobic capacity, leading to exercise-induced lactic acidosis at low exertional workloads. The subsequent buffering of lactate by bicarbonate increases carbon dioxide flux to the lungs, increasing ventilatory demand and leading to dyspnoea.

Musculoskeletal impairments decrease oxygen use at the level of the exercising muscle, reducing its aerobic capacity and leading to exercise-induced lactic acidosis at low exertional workloads. As discussed earlier, exercise-induced lactic acidosis can lead to dyspnoea through an increase in ventilatory demand.

Neuropsychological impairments may affect the experience of dyspnoea by altering the perception of breathing discomfort or by leading to a sedentary state that adversely affects the aerobic capacity of the exercising muscle.

Anaemia decreases arterial oxygen content and can thus lead to exertional dyspnoea as a consequence of a reduction in the delivery of oxygen to the exercising muscle. Anaemia may also exacerbate coexisting cardiorespiratory impairments.

Impaired renal function may lead to dyspnoea as a result of high ventilatory demand from the bicarbonate buffering of an underlying metabolic acidosis. Chronic kidney disease may also exacerbate respiratory, cardiovascular, and musculoskeletal impairments.

Obesity and weight loss may lead to sarcopaenia and, in turn, to dyspnoea take out including as a result of impairments of the muscles of ambulation and breathing.

Finally, use of medications may also affect the experience of dyspnoea by altering the perception of breathing discomfort or through adverse effects on respiratory, cardiovascular, and musculoskeletal function. 


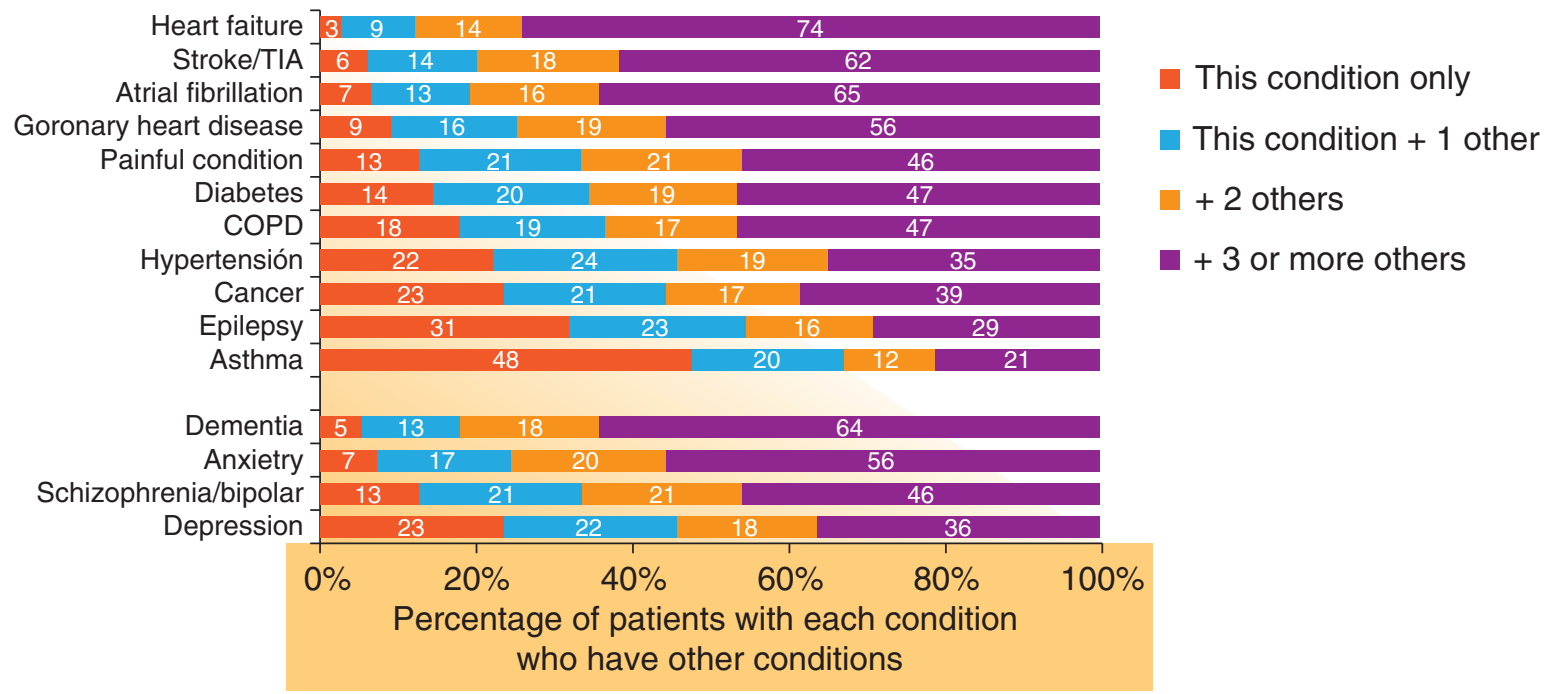

FIgURE 2A. Number of conditions experienced by patients with common, important diseases (reproduced with permission from Barnett $K^{11}$ ). COPD: chronic obstructive pulmonary disease; TIA: transient ischaemic attack.

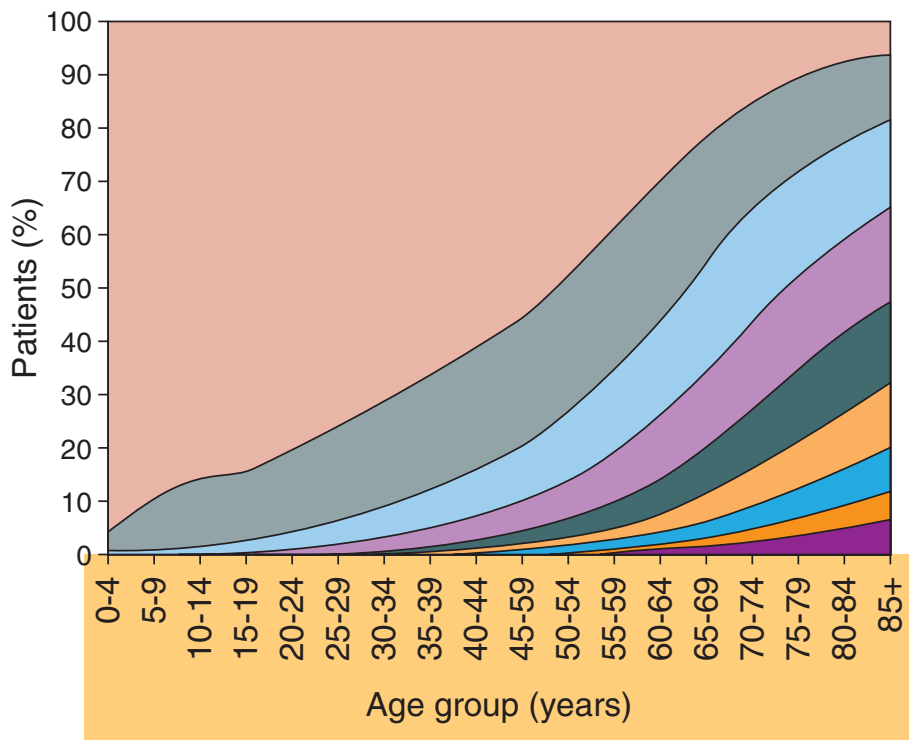

0 disorders

1 disorders

2 disorders

3 disorders

4 disorders

5 disorders

6 disorders

7 disorders

- 8 disorders

Figure 2B. Number of chronic disorders by age-group (reproduced with permission from Barnett $K^{11}$ ). 

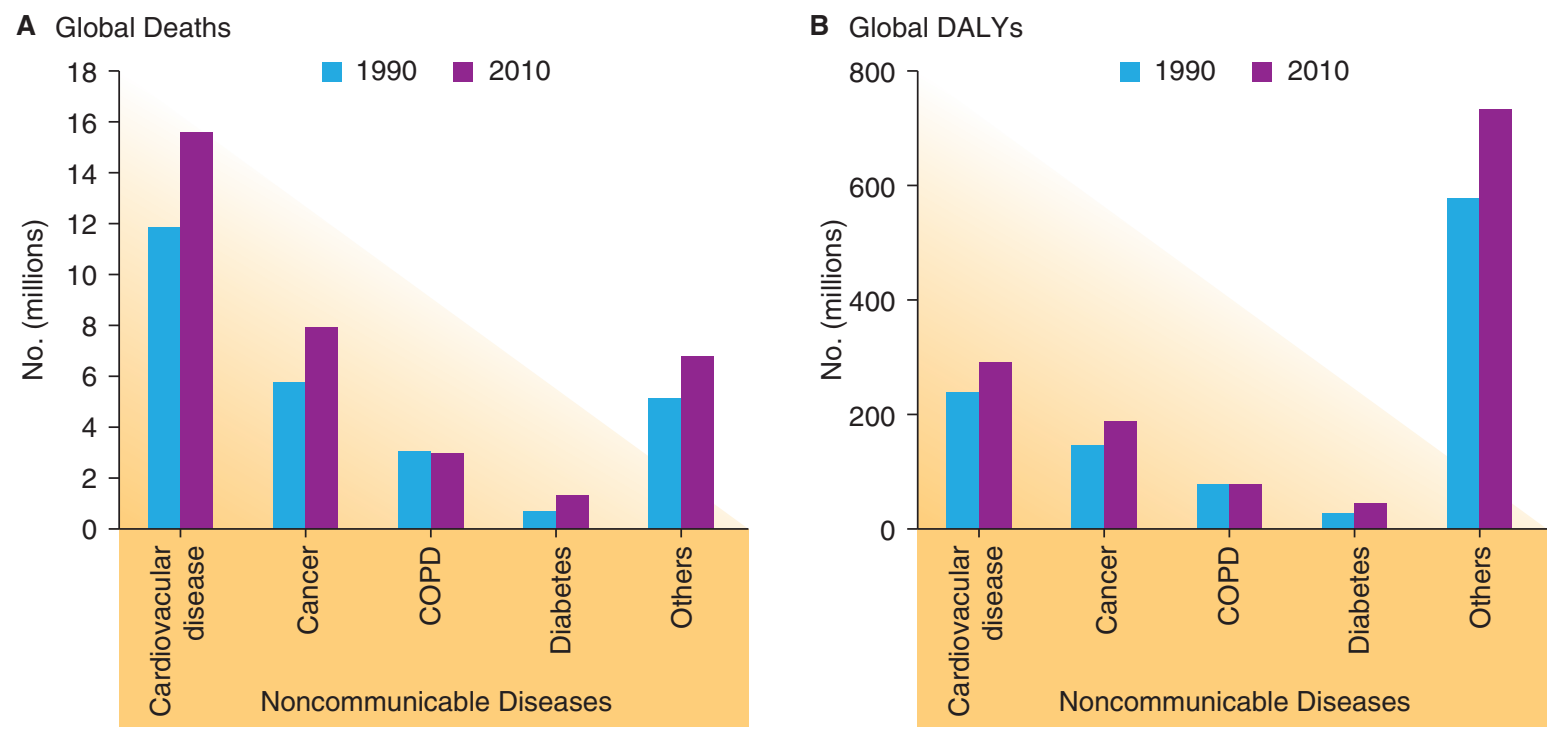

Figure 3A. Global deaths and global disability-adjusted life years (DALYs) due to noncommunicable diseases in 1990 and 2010 . DALYs are the sum of years of life lost from premature death and years lived with disability (reproduced with permission from Hunter DJ ${ }^{2}$.

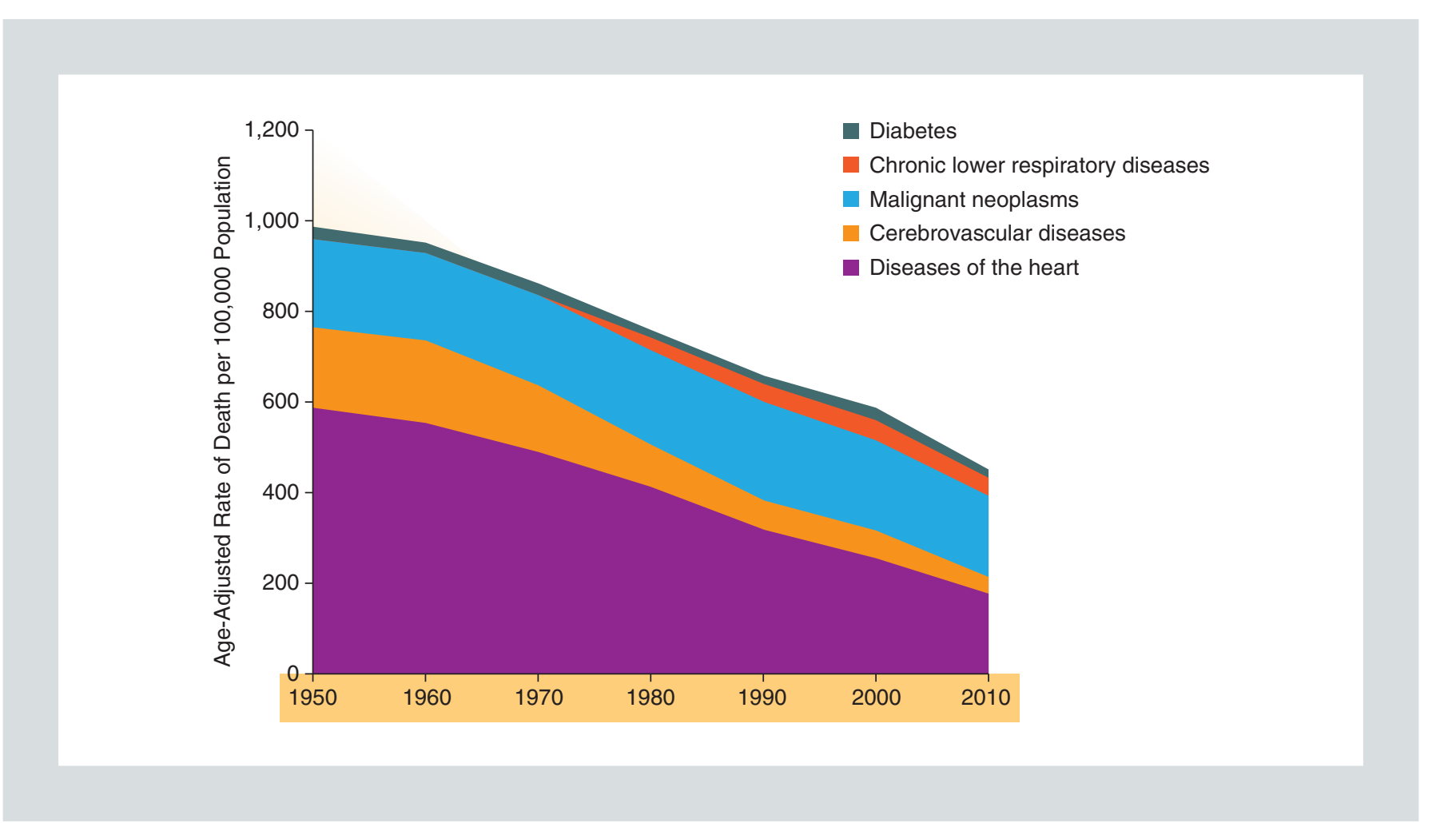

Figure 3B. Declines in rates of death from major noncommunicable diseases in the United States, 1950 to 2010 (reproduced with permission from Hunter $D J^{2}$.

COPD: chronic obstructive pulmonary disease. 
In a multivariable logistic regression model, a strong association with moderate to severe dyspnoea was found to be, in rank order, lung function, left ventricular ejection fraction, depressive symptoms and obesity, whereas respiratory muscle weakness, diastolic cardiac dysfunction, grip weakness, anxiety symptoms, and use of cardiovascular and psychoactive medications had a minor effect ${ }^{17}$.

\section{EXACERBATIONS OF DYSPNOEA}

Exacerbations of COPD are still defined as acute events characterized by a worsening of the patient's respiratory symptoms, particularly dyspnoea, beyond day-to-day variation, leading to a change in medical treatment and/or hospitalization ${ }^{14}$. Patients with COPD frequently have almost invariably chronic comorbidities, and several of these comorbidities may also exacerbate (e.g., acute heart failure, myocardial infarction, atrial fibrillation, stroke, acute kidney failure), each of them contributing to the increased morbidity and mortality not only in patients with COPD but also in patients with any of the concomitant chronic diseases. Thus, even if by definition, acute exacerbations of COPD are considered a respiratory condition, with specific reference to dyspnoea and to the organs involved (airways and lung); in fact, the exacerbations of dyspnoea may also be caused by exacerbation of concomitant chronic diseases (e.g., decompensated heart failure, arrhythmias and thromboembolisms), without even involving the airways and lung. The clinical manifestations of decompensated heart failure, arrhythmias, ischaemic heart disease (IHD), kidney failure, thromboembolism, anaemia, and even stroke and depression. Interestingly, depression is a very frequent component of multi-morbidity, creating a vicious circle with dyspnoea, so that the presence of anxiety and depression is associated with early admission to hospital in the course of a dyspnoea exacerbation because of a more intense perception of respiratory symptoms. The bottom line is that exacerbations of respiratory symptoms, and particularly dyspnoea, represent the complex pathogenic interactions between COPD and exacerbation of various concomitant chronic diseases forming the multi-morbidity, and this results in degrees of summing, overlapping or mimicking of respiratory symptoms often diagnosed as COPD exacerbation only because the presenting patients are elderly and smokers or ex-smokers (Fig. 4) ${ }^{18}$.

The first Global Initiative for Chronic $\mathrm{Ob}$ structive Lung Disease (GOLD) document that specifically introduced the important concept of COPD as pulmonary component of a systemic disease and concomitant chronic diseases due to smoking and ageing is the 2007 GOLD report ${ }^{19}$, that stated "Because COPD often develops in long-time smokers in middle age, patients often have a variety of other diseases related to either smoking or aging. COPD itself also has significant extrapulmonary (systemic) effects that lead to comorbid conditions. Thus, COPD should be managed with careful attention also paid to comorbidities and their effect on the patient's quality of life. A careful differential diagnosis and comprehensive assessment of severity of comorbid conditions should be performed in every patient with chronic airflow limitation" and devotes a specific paragraph to search and management of "comorbidities"19.

The concepts of systemic effect of inflammation in $\mathrm{COPD}^{20,21}$ and of COPD pulmonary 


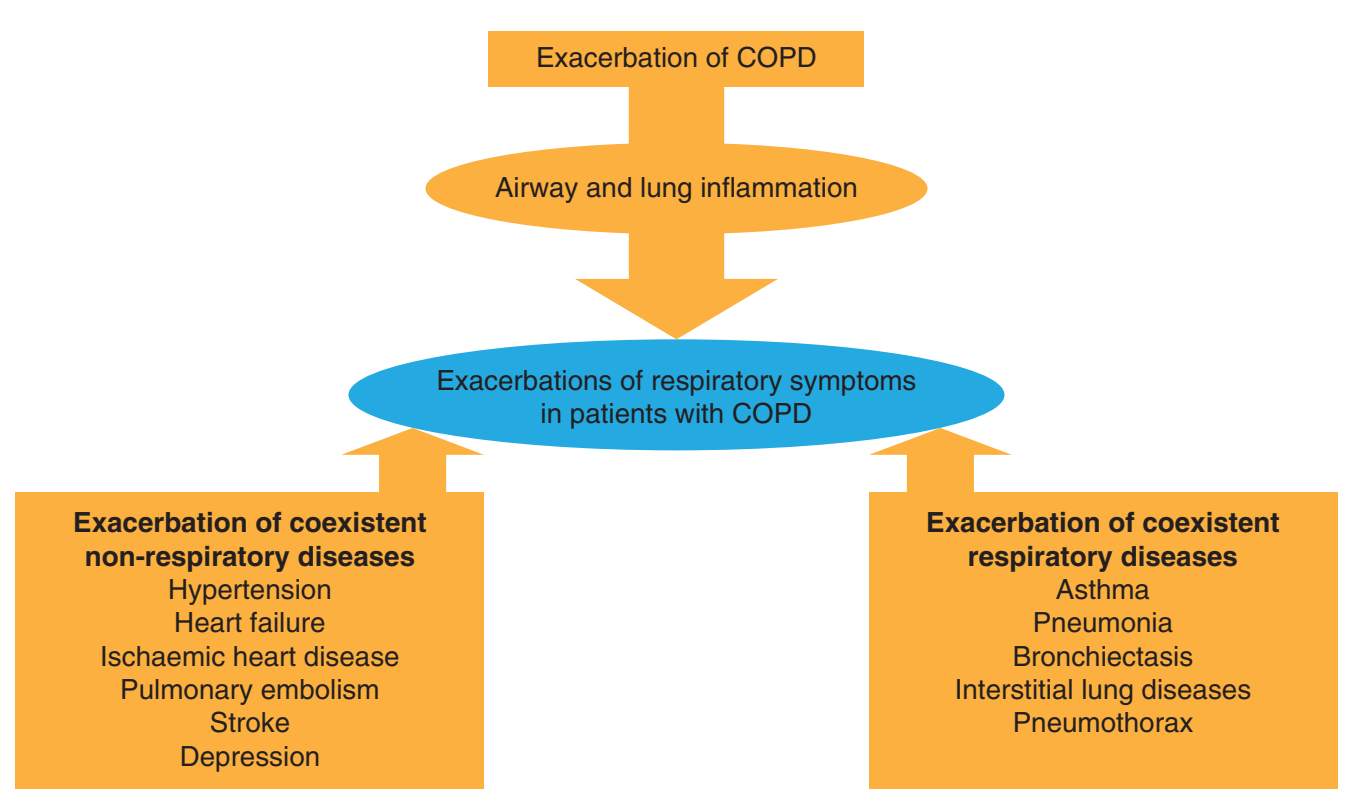

FIgURE 4. Exacerbation of respiratory symptoms in patients with chronic obstructive pulmonary disease (COPD) may be caused by respiratory infections and/or pollutants that cause acute inflammation of the airways and lung. These acute events may be correctly defined as exacerbations of COPD, but only after excluding other contributing mechanisms. Exacerbation of respiratory symptoms in patients with COPD and no comorbidities may be caused by acute independent events (e.g., pneumonia, pneumothorax, acute ischaemic heart disease and arrhythmias). These acute events should not be defined as exacerbations of COPD, but rather exacerbations of respiratory symptoms in patients with COPD, followed by a description of the cause(s) (reproduced with permission of the ERS

(C): European Respiratory Journal Apr 2013, 41 (4) 993-995; DOI: 10.1183/09031936.0018081218).

component of a multimorbid inflammatory disease $^{22,23}$ summarized the evidence collected in several clinical and epidemiologic studies that have been increasingly published starting in 2000 and that culminated in pivotal articles in major medical journals ${ }^{2,24}$.

Although the lung is usually identified as the primary target organ, smoking greatly affects other organs as cigarette smoking exposure leads to generalized endothelial injury affecting both the lungs and many other organs as the vessels, the heart and the kidney ${ }^{25,27}$, thus leading to coincident chronic injury to different organs. It is possible that in patients with
COPD, changes caused by or linked to COPD per se (such as hypoxaemia, chronic systemic inflammation, and increased oxidative stress levels) contribute to the progression of different organ injury by increasing the severity of endothelial injury ${ }^{20,21}$.

The evolution of the main concepts of GOLD documents has been nicely reviewed recently in conjunction with the $20^{\text {th }}$ anniversary of $\mathrm{GOLD}^{28}$. Regarding comorbidities, the main message of the most recent GOLD document ${ }^{14}$ is that COPD often coexists with other chronic diseases that may have a significant impact on prognosis. Some of these diseases arise independently of COPD, whereas others may 
be causally related, either with shared risk factors (e.g., ageing, smoking, inactivity, prematurity at birth, early respiratory infections), or by the simple concept that the presence of one chronic disease component of the multimorbidity may increase the risk or the severity of the other. The important message is that the management of the patient with COPD is not just the management of COPD, but must include identification and treatment of other concomitant chronic diseases. In particular, the recommendation is that the presence of comorbidities should not alter COPD treatment, and that these other concomitant chronic diseases should be treated according to single diseases guidelines regardless of the presence of COPD, but considering that the treatment of a patient with COPD is part of a multi-morbidity care plan, and thus that attention should be directed to ensure simplicity of treatment and minimize polypharmacy.

The most frequent chronic diseases that are increased and have an impact on severity and prognosis in patients with COPD are listed in table 2.

The prevalence and impact of these chronic conditions have been recently reviewed both in the GOLD document ${ }^{14}$, and in several review articles ${ }^{27,29-34}$ to which we refer.

All documents underline the concept that concomitant chronic diseases are largely misdiagnosed or undiagnosed and thus untreated in COPD patients. A concept that was firstly reported for congestive heart failure (CHF) ( $80 \%$ undiagnosed CHF in COPD) by Rutten et $\mathrm{a}^{35}$ more than 10 years ago, and recently re-addressed in review articles ${ }^{36,37}$.
TABLE 2. Most frequent chronic diseases that are increased in chronic obstructive pulmonary disease (COPD) and have an impact on severity and prognosis in patients with COPD.

\begin{tabular}{|c|c|}
\hline $\begin{array}{l}\text { Cardiovascular } \\
\text { Diseases }\end{array}$ & $\begin{array}{l}\text { Chronic heart failure } \\
\text { Ischaemic heart diseases } \\
\text { Arrhythmias } \\
\text { Peripheral artery disease } \\
\text { Stroke and transient cerebrovascular } \\
\quad \text { ischemia } \\
\text { Thromboembolism }\end{array}$ \\
\hline $\begin{array}{l}\text { Chronic respiratory } \\
\text { diseases }\end{array}$ & $\begin{array}{l}\text { Asthma } \\
\text { Bronchiectasis } \\
\text { Obstructive sleep disorders } \\
\text { Lung cancer } \\
\text { Interstitial lung diseases } \\
\text { Pulmonary hypertension } \\
\text { Tuberculosis } \\
\text { Human immunodeficiency virus (HIV) }\end{array}$ \\
\hline Metabolic diseases & $\begin{array}{l}\text { Metabolic syndrome } \\
\text { Obesity } \\
\text { Nutritional disorders }\end{array}$ \\
\hline $\begin{array}{l}\text { Central Nervous } \\
\text { system }\end{array}$ & $\begin{array}{l}\text { Anxiety and depression } \\
\text { Psychiatric diseases } \\
\text { Cognitive impairment. } \\
\text { Degenerative disorders }\end{array}$ \\
\hline Endocrine diseases & $\begin{array}{l}\text { Diabetes } \\
\text { Osteoporosis } \\
\text { Hypothyroidism }\end{array}$ \\
\hline $\begin{array}{l}\text { Gastrointestinal } \\
\text { Diseases }\end{array}$ & $\begin{array}{l}\text { Gastroesophageal reflux } \\
\text { Inflammatory bowel diseases } \\
\text { Chronic liver diseases }\end{array}$ \\
\hline Miscellaneous & $\begin{array}{l}\text { Chronic kidney diseases } \\
\text { Anaemia } \\
\text { Psoriasis }\end{array}$ \\
\hline
\end{tabular}

The prevalence of the most representative chronic diseases found in patients with COPD when properly and actively searched is reported in figure $5^{38}$.

\section{COPD IN PATIENTS WITH OTHER CHRONIC DISEASES}

While the prevalence and impact of concomitant chronic diseases in COPD have been extensively examined and described, the prevalence and impact of COPD in other chronic 


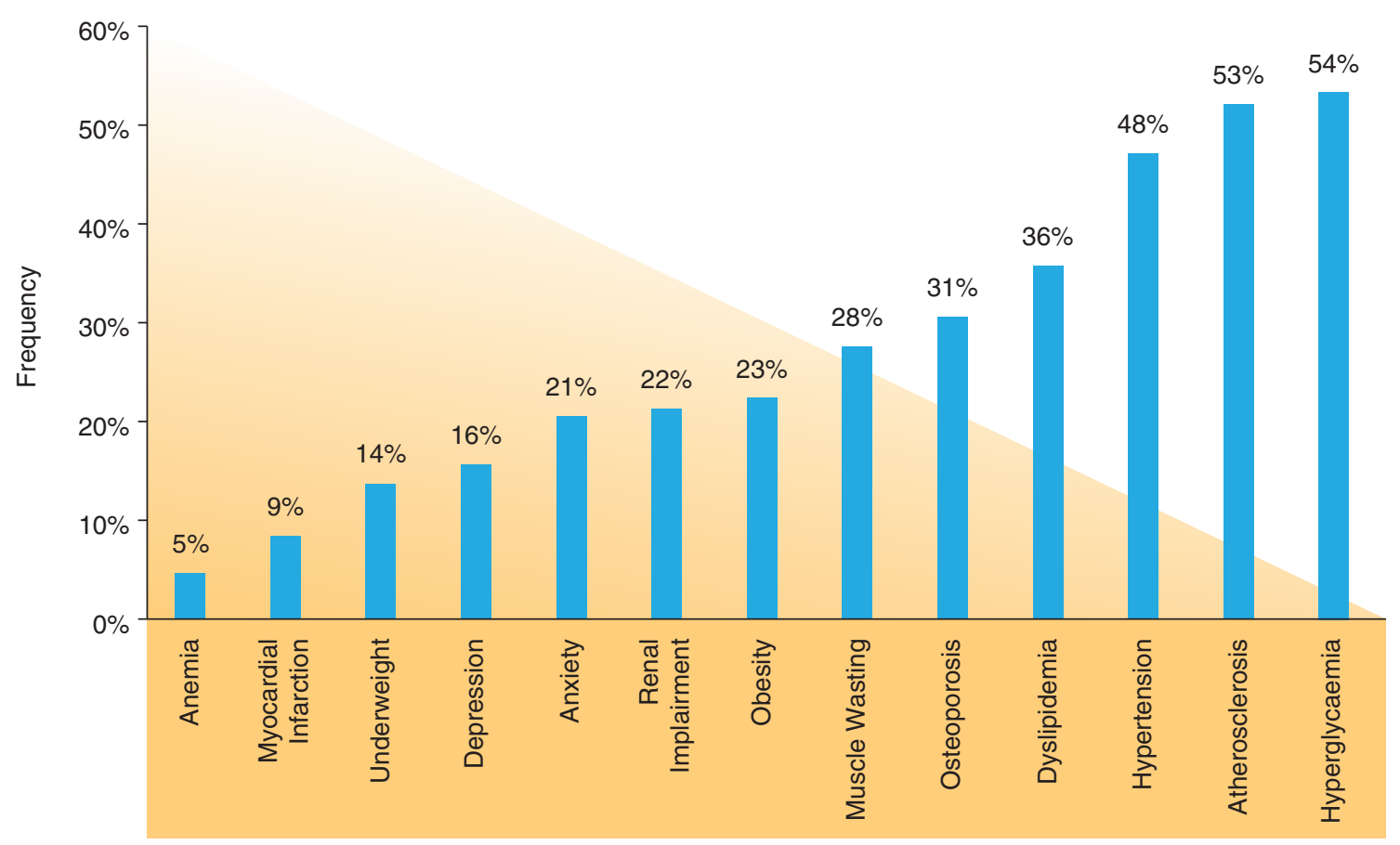

Figure 5. Prevalence of actively searched concomitant chronic diseases in patients with chronic obstructive pulmonary disease (COPD) referred to a rehabilitation centre (reprinted with permission of the American Thoracic Society. Copyright (C) 2017 American Thoracic Societyfrom Vanfleteren $\left.L E^{38}\right)$.

conditions that are part of multi-morbidity have been less investigated. Unfortunately, no randomized clinical study has been conducted in patients with any of the following concomitant chronic diseases comparing patients with or without COPD or the concomitant chronic disease.

\section{CARDIOVASCULAR DISEASES}

Because of the potential adverse effect of cardiovascular drugs, and particularly the $\mathrm{BB}$, the prevalence and impact of COPD has been more frequently investigated in cardiovascular diseases ${ }^{33,39}$.

\section{HEART FAILURE}

COPD and CHF commonly coexist in clinical practice, the prevalence of COPD among HF ranging from 12 to $40 \%{ }^{33}$. Apart from the challenging questions related to diagnosis and assessment of severity linked to overlap of common risk factors, symptoms and clinical manifestations ${ }^{14,15,33}$.

The presence of COPD in HF with both reduced and preserved ejection fraction increases burden of comorbidities, longer hospitalizations, underutilization of evidence-based medicine, and increased mortality ${ }^{40}$. 
A major focus of interest has been that key drugs for the management of HF, that the key drugs used to treat HF, while reduce hospitalizations, morbidity and mortaslity, might have piotential side-effects in patients with HF and COPD. Most studies have focused not only on $\mathrm{BB}$, but also on ACE inhibitors, and aldosterone antagonists. The bottom line of all these studies, summarized in the most recent HF guidelines, are that all drugs required for the treatment of HF are safe and effective in patients with HF and COPD, the only exception being $\mathrm{BB}$ in patients with concomitant COPD and asthma ${ }^{15}$. This is particularly true for patients with HF with reduced ejection fraction $^{39}$, whereas it remains to be properly investigated for the $50 \%$ of patients with HF and preserved ejections fraction who are treated like the former but without any evidence of efficacy and safety ${ }^{15}$.

Regarding efficacy, there are fundamental differences between the aims and efficacy of pharmacologic treatments of HF and COPD, for HF being mainly improvement of survival and quality of life, and reduction of hospitalizations ${ }^{15}$, for COPD mainly improvement of symptoms and quality of life, and reduction of exacerbations, without any effect (apart from oxygen and lung surgery in selected patients) on mortality and progression of disease ${ }^{14}$.

\section{ISCHAEMIC HEART DISEASE}

Multi-morbidity is increasingly prevalent among older adults presenting with acute myocardial infarction, and includes both cardiovascular (CV) (HF, hypertension, and arrhythmias) and non-CV (anaemia, chronic kidney disease, and depression) conditions. Hospital mortality and length of stay increase in a dose-dependent fashion with the number of $\mathrm{CV}$ and non-CV comorbidities ${ }^{41}$.

The prevalence of COPD in patients with established chronic IHD ranges from 8 to $30 \% 33$, and once again it is largely (> 80\%) undiagnosed $^{42}$.

Patients with IHD and COPD (up to 30\%) undergoing percutaneous coronary interventions or bypass, have at 5 years follow-up a 10 -fold increased mortality ( $31 \%$ versus $3.1 \%$ ), a 2-fold increased risk of revascularization $(40 \%$ versus $20 \%)$, and $>6$-fold increased risk of re-hospitalization due to HF (25\% versus $4 \%)^{43}$.

\section{ATRIAL FIBRILLATION}

Atrial fibrillation (AF) is the most common supraventricular arrhythmia in the general population and in patients with COPD as well. The prevalence of COPD in patients with $\mathrm{AF}$ ranges around 10 to $15 \%$, reaching $23.2 \%$ in patients older than 65 years and depending on the population examined (Table E3 in Roversi et al. ${ }^{33}$ ).

Evidence on patients with both diseases is limited and focuses mainly on the prognostic impact of coexisting COPD in patients with $\mathrm{AF}$, revealing a significant association with hospital admissions and all-cause mortality ${ }^{44}$. Concurrent COPD is a negative prognostic factor for AF progression from paroxysmal AF to persistent $\mathrm{AF}$, immediate and long-term success of cardioversion, and recurrence of atrial tachyarrhythmia after catheter ablation. 


\section{COPD IN COMPLEX CARDIOVASCULAR PATIENTS}

In clinical practice, complex CV patients (e.g., $\mathrm{HF}$, IHD, and AF in the same patients) are common. However, when HF, IHD, or AF are considered in the medical literature, each disease is usually analyzed separately or as a global entity under the rubric of "cardiovascular comorbidities". Therefore, data on the relationship between the "complex cardiac patient" and COPD is scarce. Given the clinical relevance of the topic, there is a pressing need for high-quality data on how best to diagnose, manage, and educate these patients.

\section{STROKE AND TRANSIENT ISCHAEMIC ATTACKS}

Cerebral small vessel disease and accumulation of brain pathology associate with cognitive decline and can lead to clinical outcomes, such as stroke, transient ischaemic attacks (TIA) and dementia. COPD is a common respiratory disease among elderly. While there is clinical and epidemiologic evidence of cerebral small vessel disease, stroke, TIAs, and (vascular) cognitive impairment in patients with $\mathrm{COPD}^{45,46}$, literature is very scarce on the presence of lung function abnormalities and/or COPD in patients with stroke or TIA, and/or dementia. Patients with stroke have several concomitant chronic diseases, and $>20 \%$ have $\mathrm{COPD}^{47}$. One interesting study hypothesized that lower respiratory function may increase the risk for small-vessel disease by lowering oxygen supply to the brain, and that lower respiratory function increases inflammatory responses in blood vessels, which may lead to atherosclerosis.
Albeit limited to women, the 26-year follow-up up study found that mid-life respiratory function and white matter lesions and lacunar infarcts in elderly women were related to lower midlife respiratory function ${ }^{48}$.

\section{PERIPHERAL ARTERY DISEASE}

A significant proportion of patients with COPD $(8.8 \%)$ have peripheral artery disease, a prevalence that is higher than the prevalence in control subjects without COPD. Peripheral artery disease is associated with a clinically relevant reduction in functional capacity and health status $^{49}$. Limited is the literature on the prevalence of COPD in patients with peripheral artery disease. However, COPD, coronary artery disease, and peripheral artery disease, when coexisting in the same patient, are positively associated with the presence of abdominal aortic aneurysm (AAA) and increase the risk of its rupture ${ }^{50}$.

\section{THROMBOEMBOLISM}

While the risk of thromboembolism and in particular of pulmonary embolism is increased in patients with stable COPD ${ }^{51}$, the size of this risk is variable in stable conditions ${ }^{52}$, but it increases during exacerbations of $\mathrm{COPD}^{53-55}$ (Fig. 6).

By contrast, interestingly, the prevalence of COPD in patients followed after a confirmed episode of venous thromboembolism is relatively low $(<10 \%)$, and these patients are not at increased risk of future recurrences or death $^{56}$. 


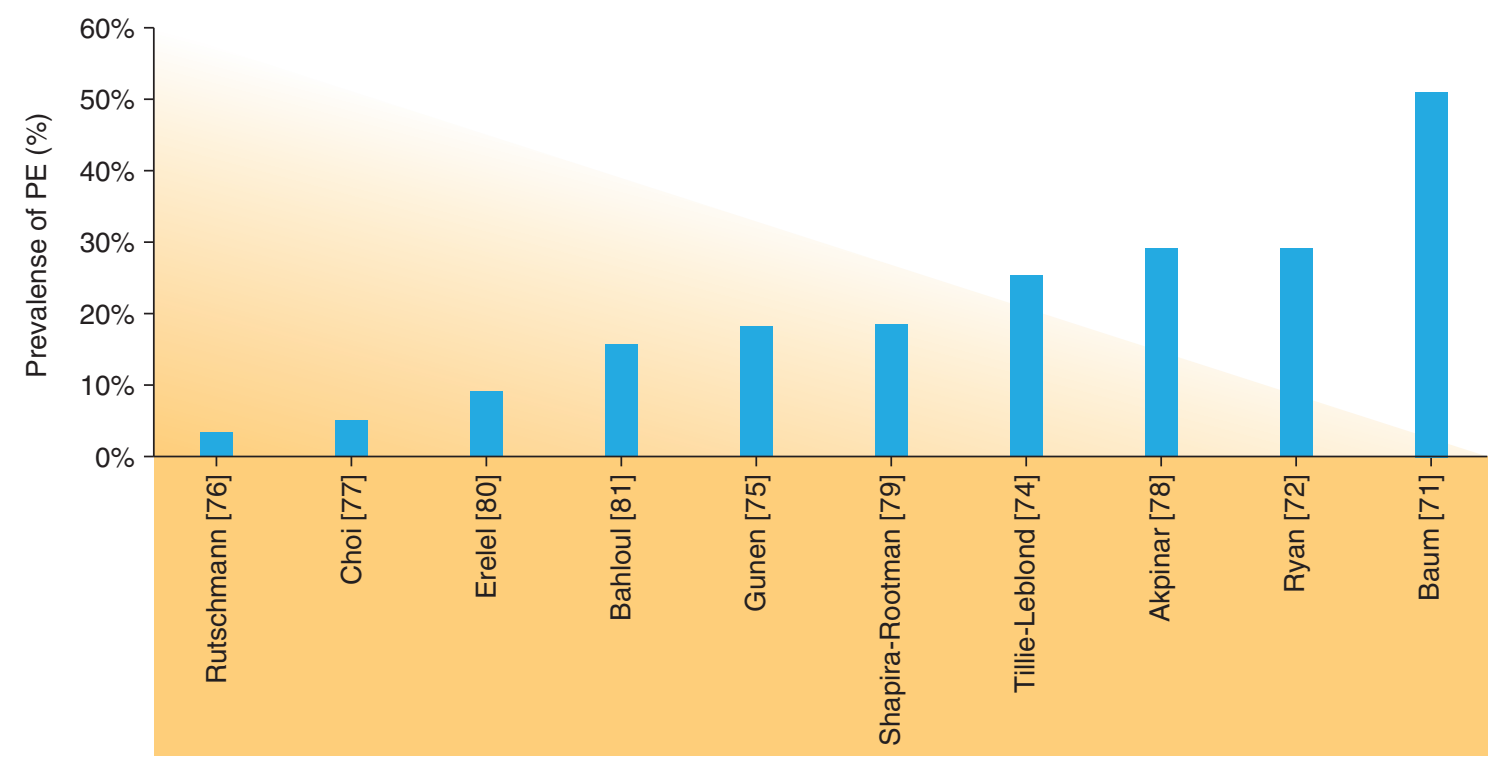

Figure 6. The prevalence of pulmonary embolism (PE) in chronic obstructive pulmonary disease (COPD) exacerbations across studies (reproduced with permission of the ERS (C): Franssen F, Vanfleteren $L^{54}$ ).

\section{CHRONIC RESPIRATORY DISEASES}

The prevalence and impact of airflow limitation and/or COPD has been extensively studied and reviewed in asthma and obstructive sleep disorders ${ }^{14,57,58}$, bronchiectasis ${ }^{59,60}$, lung cancer $^{14,61}$, interstitial lung diseases and pulmonary hypertension ${ }^{62,63}$, tuberculosis ${ }^{64}$, and human immunodeficiency virus (HIV) ${ }^{65}$, and will not be addressed in this review.

\section{METABOLIC DISEASES}

Metabolic syndrome is increased in overweight or obese COPD patients compared to matched control, and is associated with increased risk of morbidity and mortality with consequent increased risks linked to the concomitant chronic diseases linked to metabolic syndrome ${ }^{66-68}$. Even if little is known about the prevalence and impact of COPD in patients with the metabolic syndrome and/or obesity, because lung function is seldom measured in these patients, the observation that obese patients with mild COPD had more comorbid conditions suggesting that obesity and COPD may be a risk ${ }^{69,70}$.

Indeed, there are potential mechanisms of interaction between COPD and the components of the metabolic syndrome, e.g., arterial 
hypertension ${ }^{71}$, diabetes ${ }^{72}$, hyperdyslipidemia ${ }^{73}$, and overweight/obesity. All this suggest that the coexistence of COPD and metabolic syndrome or some of its components may increase the severity of its clinical manifestations and future risks ${ }^{71,72}$.

Low body mass index and reduced and abnormal diaphragmatic and skeletal mass that are associated with lower exercise capacity and higher mortality in patients with COPD may represent either a risk factor or a systemic effect of COPD ${ }^{20}$. The effects of nutritional interventions and/or rehabilitation may counteract this vicious circle $\mathrm{e}^{74-76}$.

\section{CHRONIC NEUROLOGICAL DISORDERS}

Depression and anxiety have been extensively reported as clinical manifestations of chronic diseases $^{77,78}$, but were never properly investigated mechanistically and more importantly, COPD has never been adequately investigated in patients affected by or treated because of anxiety and/or depression. Similarly, no proper studies have been conducted in the field of impact of COPD on chronic neurological degenerative disorders such as Alzheimer, Parkinson, and dementia, all potentially linked to smoking ${ }^{79}$, that represent a very important component of the multimorbid chronic elderly patient.

\section{ENDOCRINE DISEASES}

Patients with both type 1 and type 2 diabetes have reduced lung function independently from other risk factors and particularly smoking ${ }^{80}$. The relationship between type 2 diabetes and COPD is still unclear but common mechanisms may create vicious circles ${ }^{72}$.

While it is well known that osteoporosis is closely associated with COPD, and that osteoporosis and osteoporotic fractures are common in COPD patients, a recent retrospective study conducted in newly-diagnosed male osteoporotics found that COPD may actually represent the leading cause of secondary osteoporosis, more frequent than glucocorticoid use or hypogonadism, and osteoporosis-associated fractures may further deteriorate pulmonary function and thereby impair activities of daily life (ADL) of COPD patients ${ }^{81}$. Thus, the two diseases will form a vicious cycle that causes significant burdens on the patients. Osteoporosis in COPD patients and vice-versa are however largely underdiagnosed and undertreated $^{81}$.

Albeit both hypothyroidism ${ }^{82}$, and hyperthyroidism $^{83}$ may be associated with exertional dyspnoea, and fatigue can be the presenting complaint, their relationship with COPD has not been investigated.

\section{GASTROINTESTINAL DISEASES}

The most frequently investigated gastrointestinal disease in patients with COPD has been gastroesophageal reflux, that has been shown in several studies to represent a significant risk factor for symptom severity and exacerbations ${ }^{84}$. By contrast, almost no study has been conducted looking at COPD in patients with gastroesophageal reflux. 
Airway diseases are the most commonly described lung manifestations of inflammatory bowel disease (IBD). However, the similarities in disease pathogenesis and the sharing of important environmental risk factors and genetic susceptibility suggest that there is a complex interplay between IBD and airway diseases $^{85}$.

Only very recently associations between COPD and some chronic liver diseases, in particular non-alcoholic fatty liver disease (NAFLD) ${ }^{86,87}$, and viral hepathitis have been reposted ${ }^{88}$.

\section{CHRONIC KIDNEY DISEASES}

The coexistence of chronic kidney disease and COPD has been recently reviewed ${ }^{30}$. The pathophysiology of the two conditions had been previously extensively addressed in patients with respiratory failure ${ }^{89}$, whereas the effects of age and long-term smoking on renal and pulmonary function has not. One potential vicious circle between chronic kidney disease and COPD is cachexia and/or sarcopenia ${ }^{90}$.

\section{MISCELLANEOUS}

Other frequent chronic diseases that represent important component of chronic multi-morbidity in the elderly have been associated with COPD, even is the cause-effect relationship has not been established. Among these diseases it is worth mentioning psoriasis ${ }^{91}$ and rheumatoid arthritis ${ }^{92}$, possibly because in both smoking represents a major risk factor, and thus patients who develop these diseases earlier in life may be at increased risk of developing COPD later in life.

\section{CONCLUSIONS}

Multi-morbidity affects more than two thirds $2 / 3$ of elderly subjects and includes both physical and mental health conditions, as anxiety and depression, that almost invariably reduce the quality of life of these patients.

The management of a patient with any of the chronic diseases that are part of multi-morbidity is not just the management of that single presenting index disease, but must include the active search and proper treatment of concomitant chronic diseases. The presence of concomitant chronic diseases should not alter the management of the index disease, and concomitant chronic disease should be treated according to single disease guidelines regardless of the presence of the index disease, obviously with careful consideration that this choice implies complex management, polypharmacy and potential adverse effects.

Ongoing multidisciplinary hospital and home base management programs suggest that a holistic integrated approach might improve quality of life and reduce admissions and duration of stay at the hospital, and possibly death in these multimorbid patients ${ }^{93,94}$.

\section{CONFLICTS OF INTEREST}

Dr. Leonardo Fabbri reports grants, personal fees and non-financial support from Boehringer Ingelheim, grants, personal fees and non-financial support from Chiesi Farmaceutici, grants, personal fees and non-financial support from GlaxoSmithKline, grants, personal fees and non-financial support from Merck Sharp \& Dohme, grants, personal fees 
and non-financial support from Takeda, grants, personal fees and non-financial support from AstraZeneca, grants, personal fees and non-financial support from Novartis, personal fees and non-financial support from Pearl Therapeutics, grants, personal fees and non-financial support from Menarini, personal fees and non-financial support from Mundipharma, personal fees from Kyorin, personal fees from Bayer, grants, personal fees and non-financial support from Laboratori Guidotti, personal fees and non-financial support from Boston Scientific, grants, personal fees and non-financial support from Almirall, personal fees from Zambon, grants from Pfizer, grants from Dompè, grants from Malesci, grants from Biofutura Italia, grants from Vree Health Italia, outside the submitted work. Dr Bianca Beghé and Dr. Enrico Clini have nothing to disclose.

\section{REFERENCES}

1. World Health Organization (WHO). World Health Statistics 2016. http:/ www.who.int/gho/publicationsworld_health_statistics/en/.

2. Hunter DJ, Reddy KS. Noncommunicable diseases. N Engl J Med. 2013;369: 1336-43.

3. Mendenhall E, Kohrt BA, Norris SA, Ndetei D, Prabhakaran D. Non-communicable disease syndemics: poverty, depression, and diabetes among low-income populations. Lancet. 2017;389:951-63.

4. Villacampa-Fernandez P, Navarro-Pardo E, Tarin JJ, Cano A. Frailty and multimorbidity: Two related yet different concepts. Maturitas. 2017;95:31-5.

5. Multimorbidity: Assessment, Prioritisation and Management of Care for People with Commonly Occurring Multimorbidity, London, 2016.

6. Vanfleteren LW, Spruit MA, Franssen FM. Tailoring the approach to multimorbidity in adults with respiratory disease: the NICE guideline. Eur Respir J. 2017;49.

7. Rodriguez-Manas L, Feart C, Mann G et al. Searching for an operational definition of frailty: a Delphi method based consensus statement: the frailty operative definition-consensus conference project. J Gerontol A Biol Sci Med Sci. 2013;68:62-7.

8. Fried LP, Ferrucci L, Darer J, Williamson JD, Anderson G. Untangling the concepts of disability, frailty, and comorbidity: implications for improved targeting and care. J Gerontol A Biol Sci Med Sci. 2004;59:255-63.

9. Metzelthin SF, van Rossum E, de Witte LP et al. Effectiveness of interdisciplinary primary care approach to reduce disability in community dwelling frail older people: cluster randomised controlled trial. BMJ. 2013; 347:f5264.

10. Kok RM, Reynolds CF 3rd. Management of Depression in Older Adults: A Review. JAMA. 2017; 317:2114-22.
11. Barnett K, Mercer SW, Norbury M, Watt G, Wyke S, Guthrie B. Epidemiology of multimorbidity and implications for health care, research, and medical education: a cross-sectional study. Lancet. 2012; 380:37-43.

12. Brown JP, Martinez CH. Chronic obstructive pulmonary disease comorbidities. Curr Opin Pulm Med. 2016; 22:113-8.

13. Anzueto A, Miravitlles M. Pathophysiology of dyspnea in COPD. Postgrad Med. 2017;129:366-74.

14. Vogelmeier CF, Criner GJ, Martinez FJ et al. Global Strategy for the Diagnosis, Management, and Prevention of Chronic Obstructive Lung Disease 2017 Report: GOLD Executive Summary. Eur Respir J. 2017;49.

15. Ponikowski P, Voors AA, Anker SD et al. 2016 ESC Guidelines for the diagnosis and treatment of acute and chronic heart failure: The Task Force for the diagnosis and treatment of acute and chronic heart failure of the European Society of Cardiology (ESC). Developed with the special contribution of the Heart Failure Association (HFA) of the ESC. Eur J Heart Fail 2016;18:891-975.

16. Mahler D, O'Donnel D. Dyspnea: mechanisms, Measurement, and Management. $3^{\text {rd }}$ ed.. CRC Press, Taylor and Francis Group, Boca Raton Florida; 2014.

17. Miner B, Tinetti ME, Van Ness PH et al. Dyspnea in Community-Dwelling Older Persons: A Multifactorial Geriatric Health Condition. J Am Geriatr Soc. 2016:64:2042-50.

18. Beghe B, Verduri A, Roca M, Fabbri LM. Exacerbation of respiratory symptoms in COPD patients may not be exacerbations of COPD. Eur Respir J 2013;41:993-5.

19. Rabe KF, Hurd S, Anzueto A et al. Global strategy for the diagnosis, management, and prevention of chronic obstructive pulmonary disease: GOLD executive summary. Am J Respir Crit Care Med. 2007;176:532-55.

20. Agusti AG. Systemic effects of chronic obstructive pulmonary disease. Proc Am Thorac Soc. 2005;2:367-70; discussion 371-2.

21. Barnes PJ, Celli BR. Systemic manifestations and comorbidities of COPD Eur Respir J. 2009;33:1165-85.

22. Fabbri LM, Rabe KF. From COPD to chronic systemic inflammatory syndrome? Lancet. 2007; 370:797-9.

23. Fabbri LM, Luppi F, Beghe B, Rabe KF. Complex chronic comorbidities of COPD. Eur Respir J. 2008;31:204-12.

24. Beaglehole R, Horton R. Chronic diseases of adults--a call for papers. Lancet. 2005;365:1913-4.

25. Malerba M, Nardin M, Radaeli A, Montuschi P, Carpagnano GE, Clini E. The potential role of endothelial dysfunction and platelet activation in the development of thrombotic risk in COPD patients. Expert Rev Hematol. 2017;1-12.

26. Polverino F, Laucho-Contreras ME, Petersen $\mathrm{H}$ et al. A Pilot Study Linking Endothelial Injury in Lungs and Kidneys in Chronic Obstructive Pulmonary Disease. Am J Respir Crit Care Med. 2017;195:1464-76.

27. Zoccali C, Vanholder R, Massy ZA et al. The systemic nature of CKD. Nat Rev Nephrol. 2017;13:344-58.

28. Rodriguez-Roisin R, Rabe KF, Vestbo J, Vogelmeier C, Agusti A. Global Initiative for Chronic Obstructive Lung Disease (GOLD) 20th Anniversary: a brief history of time. Eur Respir J. 2017; 50.

29. Chen W, Thomas J, Sadatsafavi M, FitzGerald JM. Risk of cardiovascular comorbidity in patients with chronic obstructive pulmonary disease: a systematic review and meta-analysis. Lancet Respir Med. 2015;3:631-9.

30. Corsonello A, Aucella F, Pedone C, Antonelli-Incalzi R. Chronic kidney disease: A likely underestimated component of multimorbidity in older patients with chronic obstructive pulmonary disease. Geriatr Gerontol Int 2017.

31. Mapel D. Renal and hepatobiliary dysfunction in chronic obstructive pulmonary disease. Curr Opin Pulm Med. 2014;20:186-93.

32. Negewo NA, McDonald VM, Gibson PG. Comorbidity in chronic obstructive pulmonary disease. Respir Investig. 2015;53:249-58

33. Roversi S, Fabbri LM, Sin DD, Hawkins NM, Agusti A. Chronic Obstructive Pulmonary Disease and Cardiac Diseases. An Urgent Need for Integrated Care. Am J Respir Crit Care Med. 2016;194:1319-36. 
34. Vanfleteren L, Spruit MA, Wouters EFM, Franssen FME. Management of chronic obstructive pulmonary disease beyond the lungs. Lancet Respir Med. 2016;4:911-24.

35. Rutten FH, Cramer MJ, Grobbee DE et al. Unrecognized heart failure in elderly patients with stable chronic obstructive pulmonary disease. Eur Heart J. 2005; 26:1887-94.

36. Labonte LE, Tan WCC, Li PZ et al. Undiagnosed Chronic Obstructive Pulmonary Disease Contributes to the Burden of Health Care Use. Data from the CanCOLD Study. Am J Respir Crit Care Med. 2016;194:285-98.

37. Triest FJ, Franssen FM, Spruit MA, Groenen MT, Wouters EF, Vanfleteren LE. Poor agreement between chart-based and objectively identified comorbidities of COPD. Eur Respir J. 2015;46:1492-5.

38. Vanfleteren LE, Spruit MA, Groenen M et al. Clusters of comorbidities based on validated objective measurements and systemic inflammation in patients with chronic obstructive pulmonary disease. Am J Respir Crit Care Med. 2013;187:728-35.

39. Jaiswal A, Chichra A, Nguyen VQ, Gadiraju TV, Le Jemtel TH. Challenges in the Management of Patients with Chronic Obstructive Pulmonary Disease and Heart Failure With Reduced Ejection Fraction. Curr Heart Fail Rep. 2016;3:30-6.

40. Kwon BJ, Kim DB, Jang SW et al. Prognosis of heart failure patients with reduced and preserved ejection fraction and coexistent chronic obstructive pulmonary disease. Eur J Heart Fail. 2010;12:1339-44.

41. Alfredsson J, Alexander KP. Multiple Chronic Conditions in Older Adults with Acute Coronary Syndromes. Clin Geriatr Med. 2016;32:291-303.

42. Franssen FM, Soriano JB, Roche N et al. Lung Function Abnormalities in Smokers with Ischemic Heart Disease. Am J Respir Crit Care Med. 2016; 194:568-76.

43. Almagro P, De la Sierra A, Acosta E et al. Spirometrically confirmed COPD worsens long-term prognosis after percutaneous coronary intervention. Am J Respir Crit Care Med. 2017 (in press).

44. Proietti M, Laroche C, Drozd M et al. Impact of chronic obstructive pulmonary disease on prognosis in atrial fibrillation: A report from the EURObservational Research Programme Pilot Survey on Atrial Fibrillation (EORPAF) General Registry. Am Heart J. 2016;181:83-91.

45. Austin V, Crack PJ, Bozinovski S, Miller AA, Vlahos R. COPD and stroke: are systemic inflammation and oxidative stress the missing links? Clin Sci (Lond). 2016; 130: 1039-50.

46. Lahousse L, Tiemeier H, Ikram MA, Brusselle GG. Chronic obstructive pulmonary disease and cerebrovascular disease: A comprehensive review. Respir Med. 2015;109:1371-80.

47. Gruneir A, Griffith LE, Fisher K et al. Increasing comorbidity and health services utilization in older adults with prior stroke. Neurology. 2016:87: 2091-8.

48. Guo X, Pantoni L, Simoni M et al. Midlife respiratory function related to white matter lesions and lacunar infarcts in late life: the Prospective Population Study of Women in Gothenburg, Sweden. Stroke. 2006;37:1658-62.

49. Houben-Wilke S, Jorres RA, Bals R et al. Peripheral Artery Disease and Its Clinical Relevance in Patients with Chronic Obstructive Pulmonary Disease in the COPD and Systemic Consequences-Comorbidities Network Study. Am J Respir Crit Care Med. 2017;195: 189-97.

50. Takagi H, Umemoto T. Association of chronic obstructive pulmonary, coronary artery, or peripheral artery disease with abdominal aortic aneurysm rupture. Int Angiol. 2017;36: 322-31.

51. Kubota Y, London SJ, Cushman M et al. Lung function, respiratory symptoms and venous thromboembolism risk: the Atherosclerosis Risk in Communities Study. J Thromb Haemost. 2016;14:2394-2401.

52. Borvik T, Braekkan SK, Enga K et al. COPD and risk of venous thromboembolism and mortality in a general population. Eur Respir J. 2016;47: $473-81$.

53. Aleva FE, Voets L, Simons SO, de Mast Q, van der Ven A, Heijdra YF. Prevalence and Localization of Pulmonary Embolism in Unexplained Acute Exacerbations of COPD: A Systematic Review and Meta-analysis. Chest. 2017;151:544-54.
54. Franssen F, Vanfleteren L. Differential diagnosis and impact of cardiovascular comorbidities and pulmonary embolism during COPD exacerbations. In: Burgel P, Contoli M, López-Campos J, eds. Acute Exacerbations of Pulmonary Diseases (ERS Monograph 77), 2017.

55. Rizkallah J, Man SFP, Sin DD. Prevalence of pulmonary embolism in acute exacerbations of COPD: a systematic review and metaanalysis. Chest. 2009; 135: 786-93.

56. Le Mao R, Tromeur C, Bazire A et al. Risk of recurrent venous thromboembolism in COPD patients: results from a prospective cohort study. Eur Respir J. 2017;50.

57. Owens RL, Macrea MM, Teodorescu M. The overlaps of asthma or COPD with OSA: A focused review. Respirology. 2017;22:1073-83.

58. Postma DS, Rabe KF. The Asthma-COPD Overlap Syndrome. N Engl J Med 2015; 373:1241-9.

59. Du Q, Jin J, Liu X, Sun Y. Bronchiectasis as a Comorbidity of Chronic Obstructive Pulmonary Disease: A Systematic Review and Meta-Analysis. PLoS One. 2016;11: e0150532.

60. Gao YH, Guan WJ, Liu SX, et al. Aetiology of bronchiectasis in adults: A systematic literature review. Respirology. 2016;21:1376-83.

61. Mouronte-Roibas C, Leiro-Fernandez V, Fernandez-Villar A, Botana-Rial M, Ramos-Hernandez C, Ruano-Ravina A. COPD, emphysema and the onset of lung cancer. A systematic review. Cancer Lett. 2016;82:240-4.

62. Harari S, Elia D, Humbert M. Pulmonary hypertension in parenchymal lung diseases: any future for new therapies? Chest. 2017. DOI: 10.1016/j chest.2017.06.008.

63. Margaritopoulos GA, Antoniou KM, Wells AU. Comorbidities in interstitial lung diseases. Eur Respir Rev. 2017;26.

64. Sarkar M, Srinivasa, Madabhavi I, Kumar K. Tuberculosis associated chronic obstructive pulmonary disease. Clin Respir J. 2017;11:285-95.

65. Drummond MB, Kunisaki KM, Huang L. Obstructive Lung Diseases in HIV: A Clinical Review and Identification of Key Future Research Needs Semin Respir Crit Care Med. 2016; 37:277-88.

66. Breyer MK, Spruit MA, Hanson CK et al. Prevalence of metabolic syndrome in COPD patients and its consequences. PLoS One. 2014;9:e98013.

67. Cebron Lipovec N, Beijers RJ, van den Borst B, Doehner W, Lainscak Schols AM. The Prevalence of Metabolic Syndrome In Chronic Obstructive Pulmonary Disease: A Systematic Review. COPD. 2016;13:399-406.

68. Watz H, Waschki B, Kirsten A et al. The metabolic syndrome in patients with chronic bronchitis and COPD: frequency and associated consequences for systemic inflammation and physical inactivity. Chest. 2009; 136:1039-46.

69. Hanson C, LeVan T. Obesity and chronic obstructive pulmonary disease: recen knowledge and future directions. Curr Opin Pulm Med. 2017;23:149-53.

70. Park JH, Lee JK, Heo EY, Kim DK, Chung HS. The effect of obesity on patients with mild chronic obstructive pulmonary disease: results from KNHANES 2010 to 2012. Int J Chron Obstruct Pulmon Dis. 2017;12:757-63.

71. Kim SH, Park JH, Lee JK, Heo EY, Kim DK, Chung HS. Chronic obstructive pulmonary disease is independently associated with hypertension in men: A survey design analysis using nationwide survey data. Medicine (Baltimore). 2017;96:e6826.

72. Cazzola M, Rogliani P, Calzetta L, Lauro D, Page C, Matera MG. Targeting Mechanisms Linking COPD to Type 2 Diabetes Mellitus. Trends Pharmacol Sci. 2017.

73. Kupeli E, Ulubay G, Ulasli SS, Sahin T, Erayman Z, Gursoy A. Metabolic syndrome is associated with increased risk of acute exacerbation of COPD a preliminary study. Endocrine. 2010; 38:76-82.

74. Cebron Lipovec N, Schols AM, van den Borst B et al. Sarcopenia in Advanced COPD Affects Cardiometabolic Risk Reduction by Short-Term High-intensity Pulmonary Rehabilitation. J Am Med Dir Assoc. 2016;17:814-20.

75. Ferreira IM, Brooks D, White J, Goldstein R. Nutritional supplementation for stable chronic obstructive pulmonary disease. Cochrane Database Syst Rev. 2012;12: CD000998.

76. Gunay E, Kaymaz D, Selcuk NT, Ergun P, Sengul F, Demir N. Effect of nutritional status in individuals with chronic obstructive pulmonary disease undergoing pulmonary rehabilitation. Respirology. 2013;18:1217-22. 
77. Connolly MJ, Yohannes AM. The impact of depression in older patients with chronic obstructive pulmonary disease and asthma. Maturitas. 2016; 92:9-14.

78. Usmani ZA, Carson KV, Heslop K, Esterman AJ, De Soyza A, Smith BJ. Psychological therapies for the treatment of anxiety disorders in chronic obstructive pulmonary disease. Cochrane Database Syst Rev. 2017;3:CD010673.

79. G SB, Choi S, Krishnan J, K R. Cigarette smoke and related risk factors in neurological disorders: An update. Biomed Pharmacother. 2017; 85:79-86.

80. Kinney GL, Black-Shinn JL, Wan ES et al. Pulmonary function reduction in diabetes with and without chronic obstructive pulmonary disease. Diabetes Care. 2014; 37:389-95.

81. Okazaki R, Watanabe R, Inoue D. Osteoporosis Associated with Chronic Obstructive Pulmonary Disease. J Bone Metab. 2016;23:111-20.

82. Sadek SH, Khalifa WA, Azoz AM. Pulmonary consequences of hypothyroidism. Ann Thorac Med. 2017;12:204-8.

83. Zuhur SS, Baykiz D, Kara SP, Sahin E, Kuzu I, Elbuken G. Relationship Among Pulmonary Hypertension, Autoimmunity, Thyroid Hormones and Dyspnea in Patients With Hyperthyroidism. Am J Med Sci. 2017;353: 374-80.

84. Chen Y. Gastroesophageal reflux disease and non-digestive tract diseases. Expert Rev Gastroenterol Hepatol. 2015;9:685-92.

85. Vutcovici M, Brassard P, Bitton A. Inflammatory bowel disease and airway diseases. World J Gastroenterol. 2016;22:7735-41.
86. Lonardo A, Nascimbeni F, Ponz de Leon M. Nonalcoholic fatty liver disease and COPD: is it time to cross the diaphragm? Eur Respir J. 2017; 49.

87. Viglino D, Jullian-Desayes I, Minoves M et al. Nonalcoholic fatty liver disease in chronic obstructive pulmonary disease. Eur Respir J. 2017;49.

88. Mekov EV, Petkov RE, Kostadinov DT, Antonov KA, Jelev DT. Chronic Obstructive Pulmonary Disease and Hepatitis C. Folia Med (Plovdiv). 2017; 59:132-8.

89. Husain-Syed F, Slutsky AS, Ronco C. Lung-Kidney Cross-Talk in the Critically Ill Patient. Am J Respir Crit Care Med. 2016;194:402-14.

90. Yoshida T, Delafontaine P. Mechanisms of Cachexia in Chronic Disease States. Am J Med Sci. 2015;350:250-6.

91. Li X, Kong L, Li F et al. Association between Psoriasis and Chronic Obstructive Pulmonary Disease: A Systematic Review and Meta-analysis. PLoS One. 2015;10:e0145221.

92. Ungprasert $\mathrm{P}$, Srivali N, Cheungpasitporn W, Davis Iii JM. Risk of incident chronic obstructive pulmonary disease in patients with rheumatoid arthritis: A systematic review and meta-analysis. Joint Bone Spine. 2016;83:290-4.

93. Bourbeau J, Kessler R, Casan P, Koehler D. COMET: A multicomponent home-based disease-management program vs routine care in severe COPD. Eur Respir J. 2017 (in press).

94. Rose L, Istanboulian L, Carriere L et al. Program of Integrated Care for Patients with Chronic Obstructive Pulmonary Disease and Multiple Comorbidities (PIC COPD+): A Randomized Controlled Trial. Eur Respir J. 2017 (in press). 